(2) Open Access Full Text Article

ORIGINAL RESEARCH

\title{
Assessment of vitreous drug concentration in the porcine eye following intracameral injection or irrigation with moxifloxacin
}

This article was published in the following Dove Press journal:

Clinical Ophthalmology

8 July 2013

Number of times this article has been viewed

\section{Kazuki Matsuura' \\ Yoshitsugu Inoue ${ }^{2}$ \\ Shin-ichi Sasaki ${ }^{3}$ \\ Yoshio $\mathrm{Hata}^{4}$ \\ Nami Ohmura ${ }^{4}$ \\ Takahiro Gotou ${ }^{4}$ \\ 'Nojima Hospital, Kurayoshi, Tottori, Japan; ${ }^{2}$ Tottori University, Yonago, Tottori, Japan; ${ }^{3}$ Oki Hospital, Okinoshima, Oki, Shimane, Japan; ${ }^{4}$ Division of Integrative Bioscience, Institute of Regenerative Medicine and Biofunction, Tottori University Graduate School of Medical Sciences, Yonago, Tottori, Japan}

Introduction: Posterior capsule rupture causes instant vitreous contamination, resulting in endophthalmitis. However, transfer of intracameral moxifloxacin (MFLX) to the vitreous has not been examined in detail. We investigated vitreous antibiotic concentrations following intracameral MFLX in both ruptured and intact posterior capsular eyes.

Methods: Experiment 1: Intraocular lenses were inserted into 21 extracted porcine eyes by one of the following three methods: (1) Irrigation: Throughout surgery, 33-fold diluted MFLX irrigation solution ( $150 \mu \mathrm{g} / \mathrm{mL}$ ) was used; (2) Bag and chamber flushing: After surgery, the anterior chamber and area behind the intraocular lenses were irrigated with 30-fold diluted MFLX (167 $\mu \mathrm{g} / \mathrm{mL})$ using a $5 \mathrm{~mL}$ syringe; (3) Simple injection: Tenfold diluted MFLX (50 $\mu \mathrm{g}$ in $0.1 \mathrm{~mL}$ ) was injected intracamerally at the conclusion of surgery. The eyeballs were frozen and the anterior, central, and posterior portions of the vitreous were cubed. After defrosting, concentrations were measured using high-performance liquid chromatography. Experiment 2: The same procedure was conducted for 18 eyes in which the posterior capsule had been ruptured.

Results: Experiment 1: Transfer of intracameral MFLX to the anterior vitreous was approximately $1 \%(1.56-2.20 \mu \mathrm{g} / \mathrm{mL})$ regardless of the administration method. Experiment 2: MFLX reached a high concentration in the vitreous with irrigation solution administration (maximum $30.22 \mu \mathrm{g} / \mathrm{mL}$ ). The concentrations reached by simple injection or flushing were significantly less than those obtained by irrigation.

Conclusion: With an intact posterior capsule, intracameral MFLX exhibited limited effects on vitreous concentration. Despite the fact that the risk of infection clearly increases in cases of ruptured capsule, no special infection prevention protocol has been proposed. It was confirmed that irrigation solution caused vitreous contamination in ruptured eyes within only a short irrigation time. In this case, intracameral administration did not necessarily achieve preventive concentrations for endophthalmitis, but it appears that an effective drug concentration can be achieved in the vitreous by the administration of irrigation solution.

Keywords: moxifloxacin, intracameral injection, irrigation, vitreous concentration, posterior capsular rupture

\section{Introduction}

Intracameral contamination can cause vitreous bacterial infection, leading to endophthalmitis. However, when intraoperative contamination is contained within the anterior chamber, endophthalmitis is unlikely. While inducing endophthalmitis experimentally requires the intracameral injection of $>10,000$ bacteria, infection has been established by direct injection of merely five bacteria into the vitreous. ${ }^{1}$ This is because intracameral bacteria are eliminated from the anterior chamber along
Correspondence: Kazuki Matsuura Nojima Hospital, 27I4-I Sesaki-machi, Kurayoshi-city, Tottori 682-0863, Japan $\mathrm{Tel}+8 \mid 85822623$ |

Fax +8I 858226843

Email i-mnys200।@za.ztv.ne.jp or matsu224@ncn-k.net which permits unrestricted noncommercial use, provided the original work is properly cited. 
with aqueous humor, and is also due to the presence of intracameral immune cells such as macrophages. If bacteria are trapped intraoperatively behind the lens (intracapsular), they may evade these protective mechanisms because they are isolated from the flow of aqueous humor. Therefore, in the case of highly virulent bacteria, these will break through the posterior capsule and contaminate the vitreous, causing acute endophthalmitis. ${ }^{2}$ If the bacteria are of low virulence (eg, Propionibacterium acnes), they will remain in this area for a long time, causing late infection. ${ }^{3}$ Successive reports have been published regarding the safety and effects of intracameral injection with cefuroxime, and this method has become popular, particularly in Europe. A fourth-generation new broad-spectrum quinolone, moxifloxacin (MFLX), has come to be commonly selected in recent years for intracameral injection, mainly in North America. ${ }^{4-7}$ There have been no reports of MFLX-related allergies or cytoxicity, and commercial MFLX is an isotonic drug that does not contain preservatives. In addition, while drugs such as cefuroxime, aminoglycoside, and vancomycin are time dependent, MFLX is concentration dependent, exhibiting effects when the minimum inhibitory concentration is exceeded for approximately 2 hours. ${ }^{6}$ In other words, MFLX is a suitable choice as an intracameral administrative agent because the anterior chamber is characterized by rapid drug turnover.

It has recently been indicated that hydrodissection can cause the formation of anterior hyaloid membrane tears (AHTs), leading to instant intraoperative vitreous contamination, ${ }^{8}$ which is also considered to occur frequently in cases of posterior capsule rupture. In this case, antibiotic concentration in the vitreous directly after surgery is important, but transfer of intracameral antibiotics to the vitreous has not been examined extensively. Vitreous drug concentrations have been reported as $0.10 \mu \mathrm{g} / \mathrm{mL}^{9}$ and $0.23 \mu \mathrm{g} / \mathrm{mL}^{10}$ with the use of eye drops, $1.6 \mu \mathrm{g} / \mathrm{mL}^{9}$ with oral administration, and approximately $1.68 \mu \mathrm{g} / \mathrm{mL}^{11}$ with intravenous administration, which are below the minimum inhibitory concentration for important pathogens. Thus, an ex vivo model was used to measure MFLX vitreous concentration directly after intracameral administration, with both intact and ruptured posterior capsules.

\section{Methods}

\section{Experiment I (intact)}

Intraocular lenses (IOLs) were inserted into 21 extracted porcine eyes after normal phacoemulsification and aspiration, with routine hydrodissection performed using $3 \mathrm{~mL}$ of solution. The eyes were divided into three groups of seven each, and MFLX was administered intracamerally.
The following three methods of administration were used: (1) Irrigation: Throughout surgery, 33-fold diluted MFLX irrigating solution (150 $\mu \mathrm{g} / \mathrm{mL})$ was used. (2) Bag and chamber (BC) flushing: ${ }^{12}$ After surgery, the anterior chamber, including the area behind IOL, was irrigated with 30-fold diluted MFLX (167 $\mu \mathrm{g} / \mathrm{mL})$ using a $5 \mathrm{~mL}$ syringe for hydration. (3) Simple injection: Tenfold diluted MFLX ( $50 \mu \mathrm{g}$ in $0.1 \mathrm{~mL}$ ) was injected intracamerally at the conclusion of surgery (below the anterior capsule). A few minutes after administration, the eyeballs were frozen to $-60^{\circ} \mathrm{C}$, and the anterior, central, and posterior portions of the vitreous were cut into cubes of approximately $3 \mathrm{~mm}$. After defrosting the vitreous, concentrations were measured using high-performance liquid chromatography (Figure 1A). The Mann-Whitney $U$-test was used for statistical analysis.

\section{Experiment 2 (rupture)}

After removing the lenses of 18 extracted porcine eyes with normal phacoemulsification and aspiration, hooks were inserted from side ports, and holes of approximately $2 \mathrm{~mm}$ were created in the posterior capsule at the final stage of irrigation and aspiration. IOLs were inserted after injecting viscoelastic material, and the intracameral viscoelastic material was aspirated using irrigation and aspiration chips. Because surgeries were performed in the same manner as general human surgeries, accurate measurement of total irrigated solution volume was difficult. To maintain uniformity, irrigation time after creation of posterior rupture was established at 5 and 10 seconds before and after IOL insertion. As in Experiment 1, the eyes were separated into three groups, and intracameral administration of MFLX was performed. Subsequent steps were as in Experiment 1 (Figure 1B).

\section{Drug preparation}

Diluted solutions were created with a balanced salt solution (BSS Plus, Alcon, Fort Worth, TX, USA) and commercially available self-preserved Vigamox ${ }^{\mathrm{TM}}$ (Alcon Inc, Hünenberg, Switzerland). Irrigation was conducted as follows: three bottles of commercially available self-preserved Vigamox ${ }^{\mathrm{TM}}$ $(5.0 \mathrm{~mL})$ were injected into one bottle of BSS Plus $(500 \mathrm{~mL})$. BC flushing: $1.0 \mathrm{~mL}$ Vigamox $^{\mathrm{TM}}$ in $29.0 \mathrm{~mL}$ BSS Plus was prepared. Simple injection: $1.0 \mathrm{~mL}$ Vigamox $^{\mathrm{TM}}$ in $9.0 \mathrm{~mL}$ BSS Plus was prepared.

\section{Irrigation}

When 33 -fold diluted $(150 \mu \mathrm{g} / \mathrm{mL})$ irrigation solution is used, intracameral concentration is approximately $150 \mu \mathrm{g} / \mathrm{mL}$ because the entire solution irrigating the eye is $150 \mu \mathrm{g} / \mathrm{mL}$. 


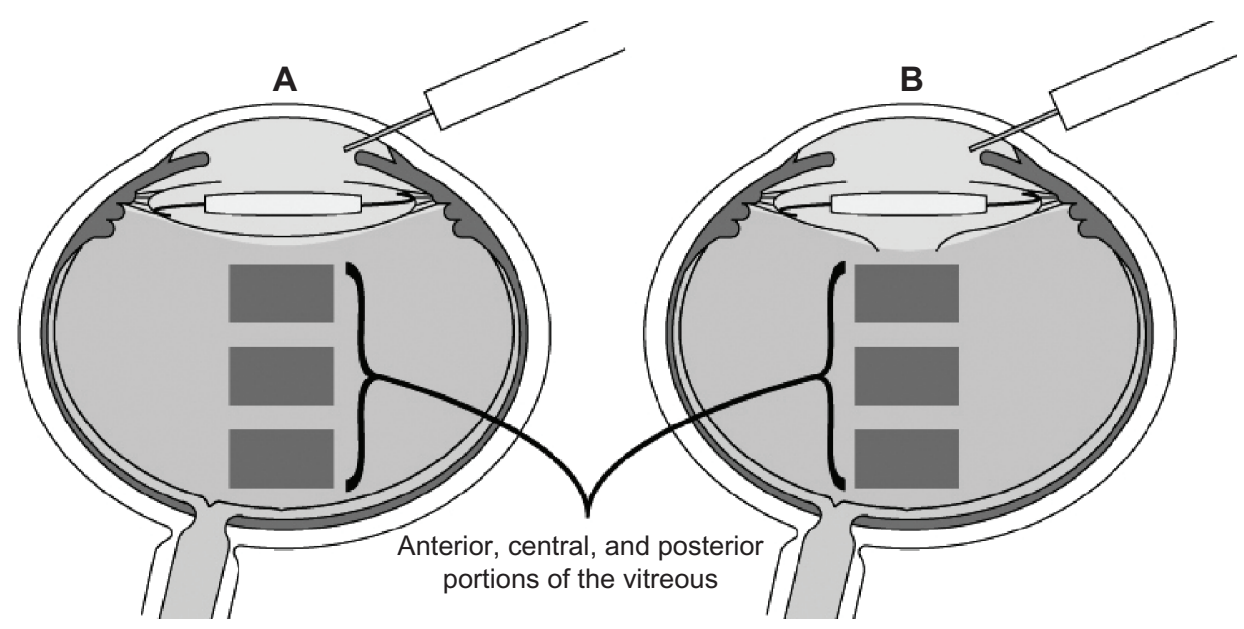

Figure I After administration using three different methods, eyeballs were frozen at $-60^{\circ} \mathrm{C}$ and the anterior, central, and posterior portions of the vitreous were cut into cubes of approximately $3 \mathrm{~mm}$ in both intact $(\mathbf{A})$ and ruptured eyes $(\mathbf{B})$.

BC flushing: When the eye is flushed with 30 -fold diluted solution (approximately $167 \mu \mathrm{g} / \mathrm{mL}$ ), approximately $90 \%$ of the anterior chamber is replaced, and the intracameral concentration is approximately $150 \mu \mathrm{g} / \mathrm{mL} .{ }^{12}$ Simple injection: When $0.1 \mathrm{~mL}$ of the tenfold diluted solution $(50 \mu \mathrm{g}$ in $0.1 \mathrm{~mL}$ ) is injected, it is diluted approximately 3.3 -fold within the anterior chamber, and the intracameral concentration becomes approximately $150 \mu \mathrm{g} / \mathrm{mL} .^{12}$ Thus, it is predicted that intracameral concentration will be approximately $150 \mu \mathrm{g} / \mathrm{mL}$ with all the above methods.

\section{High-performance liquid chromatography set-up}

The method employed a TSKgel ODS-80TM 5- $\mu \mathrm{m}$ column $(250 \times 4.6 \mathrm{~mm})$ maintained at $40^{\circ} \mathrm{C}$ and a mobile phase comprising a mixture of acetonitrile and citric buffer $(\mathrm{pH}=3.0)$ at a flow rate of $0.8 \mathrm{~mL} / \mathrm{min}$. Fluorescence detection was performed at excitation and emission wavelengths of $290 \mathrm{~nm}$ and $470 \mathrm{~nm}$, respectively.

\section{Results Experiment I}

Transfer of intracameral MFLX to the anterior vitreous was approximately $>1 \%(1.56-2.20 \mu \mathrm{g} / \mathrm{mL})$, regardless of the administration method. No significant difference was observed among any of the groups with regard to anterior, central, or posterior vitreous MFLX concentrations (Table 1 and Figure $2 \mathrm{~A}-\mathrm{C}$ ).

\section{Experiment 2}

Anterior, central and posterior vitreous MFLX concentrations in the irrigation group were significantly higher than those in the simple injection group $(P=0.002, P=0.015, P=0.026$ respectively). The irrigation group exhibited significantly higher MFLX concentration than the flushing group in the central vitreous $(P=0.026)$ (Table 1 and Figure $2 \mathrm{~A}-\mathrm{C}$ ).

When Experiments 1 and 2 were compared, it was found that among the irrigation groups, the rupture group exhibited significantly higher values compared with the intact group for the anterior and central vitreous $(P=0.001, P=0.001$, respectively) (Table 1 and Figure $2 \mathrm{~A}-\mathrm{C}$ ).

\section{Discussion}

In recent years, anticipation has grown regarding the increasing use of intracameral injection of cefuroxime to reduce the risk of endophthalmitis, particularly in Europe. Moreover, the number of reports regarding intracameral MFLX has also increased. The simple intracameral injection method, which uses small doses of approximately $0.1 \mathrm{~mL}$ of a highly concentrated solution, is common in both Europe and North America. We reported previously that $\mathrm{BC}$ flushing using intracameral MFLX irrigates the anterior chamber and the area behind the IOL. ${ }^{12}$ The total displacement method of administration (BC flushing) resulted in a stable concentration because there was little individual difference in the actual intracameral injection. Thus, we prefer to use BC flushing for the final surgical intracameral injection of MFLX, rather than simple injection.

It has also been reported that the administration of irrigation solution results in inadequate effects because intracameral administration of irrigation solution is more likely to lead to low concentrations than more common methods of intracameral administration. ${ }^{13}$ This occurs because large doses of antibiotics are required to achieve 
Table I Average antibiotic concentration in anterior, central, and posterior vitreous ( \pm standard error)

\begin{tabular}{|c|c|c|c|}
\hline & Anterior & Central & Posterior \\
\hline \multicolumn{4}{|l|}{ Intact } \\
\hline Irrigation & $\begin{array}{l}1.80 \pm 0.81 \mu g / \mathrm{mL} \\
\left(\begin{array}{l}1.76,0.68,1.84,6.44, \\
0.24,0.44,1.28\end{array}\right)\end{array}$ & 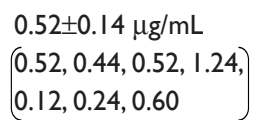 & $\left.\begin{array}{l}0.56 \pm 0.18 \mu \mathrm{g} / \mathrm{mL} \\
(0.80,0.24,0.40,1.08) \\
0.16,1.28,0.16\end{array}\right)$ \\
\hline BC flushing & $\begin{array}{l}2.20 \pm 0.80 \mu \mathrm{g} / \mathrm{mL} \\
\left(\begin{array}{l}0.56,0.36,2.12,2.98 \\
1.96,0.90,6.48\end{array}\right)\end{array}$ & $\left.\begin{array}{l}0.96 \pm 0.40 \mu \mathrm{g} / \mathrm{mL} \\
(0.14,0.18,1.06,1.26, \\
0.36,0.50,3.14\end{array}\right)$ & 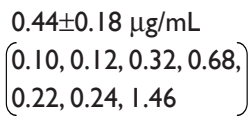 \\
\hline Simple & $\begin{array}{l}1.56 \pm 0.32 \mu \mathrm{g} / \mathrm{mL} \\
\left(\begin{array}{l}3.10,0.58,1.02,1.38 \\
1.06,2.28,1.56\end{array}\right)\end{array}$ & 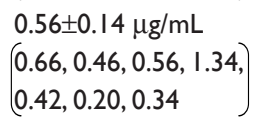 & 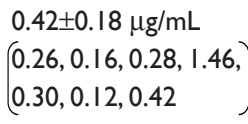 \\
\hline \multicolumn{4}{|l|}{ Ruptured } \\
\hline Irrigation & $\begin{array}{c}20.63 \pm 3.1 \mu \mathrm{g} / \mathrm{mL} \\
\left(\begin{array}{l}12.86,20.00,30.22, \\
16.21,29.69,14.78\end{array}\right)\end{array}$ & $\begin{array}{c}16.12 \pm 4.16 \mu \mathrm{g} / \mathrm{mL} \\
\left(\begin{array}{l}25.26,16.26,29.97 \\
2.86,8.17,14.18\end{array}\right)\end{array}$ & $\left.\begin{array}{c}6.43 \pm 1.62 \mu \mathrm{g} / \mathrm{mL} \\
4.96,6.72,7.83, \\
12.37,6.51,0.16\end{array}\right)$ \\
\hline BC flushing & $\left.\begin{array}{c}10.67 \pm 4.03 \mu \mathrm{g} / \mathrm{mL} \\
(0.35,0.52,16.59, \\
7.96,25.87,12.72\end{array}\right)$ & $\left.\begin{array}{l}4.61 \pm 2.05 \mu \mathrm{g} / \mathrm{mL} \\
(0.17,1.22,2.12, \\
6.48,13.81,3.88\end{array}\right)$ & $\left.\begin{array}{c}2.46 \pm 1.25 \mu \mathrm{g} / \mathrm{mL} \\
(0.10,1.20,0.32, \\
1.52,8.25,3.34\end{array}\right)$ \\
\hline Simple & $\left.\begin{array}{l}2.71 \pm 0.83 \mu \mathrm{g} / \mathrm{mL} \\
(0.05,4.03,0.13, \\
4.09,4.40,3.54\end{array}\right)$ & $\left.\begin{array}{l}2.59 \pm 0.97 \mu \mathrm{g} / \mathrm{mL} \\
(0.03,5.76,0.10, \\
4.57,3.45,1.62\end{array}\right)$ & $\left.\begin{array}{c}0.96 \pm 0.32 \mu \mathrm{g} / \mathrm{mL} \\
0.04,1.94,0.07 \\
1.56,1.36,0.78\end{array}\right)$ \\
\hline
\end{tabular}

Note: Individual data are displayed within brackets.

Abbreviation: $\mathrm{BC}$, bag and chamber.

high concentrations with irrigation solution administration. However, many reports of irrigation solution administration involve time-dependent vancomycin, and the administration of vancomycin irrigation solution is a comparatively popular choice for surgeons. ${ }^{14}$ We believe that time-dependent agents such as those in conventional use are unfit for use in the anterior chamber, which exhibits fast drug turnover, ${ }^{15}$ and that concentration-dependent MFLX is more suitable. However, because no reports have verified the effects of irrigation solution administration with MFLX, its effects are probably underestimated.

\section{Intact posterior capsule}

Although migration from intracameral administration and irrigation solution administration to the vitreous did not yield concentrations as high as we had predicted, data varied greatly and the maximum concentration in the anterior vitreous in this study was $6.44 \mu \mathrm{g} / \mathrm{mL}$, a relatively high value (Table 1 ). The experiments that we conducted did not confirm the presence of AHT; however, because hydrodissection was conducted with as much as $3 \mathrm{~mL}$ of solution, AHTs were possibly formed in several eyes. Variations in concentration may have been due to differences in the extent of AHT formation and individual variation in weakness of the zonule. When the posterior capsule was intact, intracameral administration did not result in adequate migration to the vitreous; however, as increased vitreous contamination are less likely to occur in eyes resistant to increase in drug concentration, low vitreous concentrations could not be considered as a problem. Vitreous drug concentration inevitably increases in eyes susceptible to vitreous contamination, such as those in which AHTs have formed or those with a weak zonule. Because vitreous half-life is predicted to be considerably longer than intracameral half-life, ${ }^{16}$ it can be anticipated to cover a fair proportion of pathogens even at these concentrations. However, effects against resistant bacteria such as methicillin-resistant Staphylococcus aureus and methicillin-resistant coagulase-negative Staphylococci cannot be anticipated.

\section{Ruptured posterior capsule}

While the ruptured capsule model in this study was based on the image of posterior capsule rupture after eliminating the cortex and irrigation time was relatively short, a considerable amount of irrigation solution entered the vitreous. When time and effort are taken to treat the residual nuclei and cortex, even more irrigation solution should enter the vitreous. In contrast, with simple injection, because the ruptured capsule site where the tip of the needle is inserted to inject the solution under the anterior capsule is covered by IOL, drug solution is not transferred to the vitreous. With BC flushing, approximately $2 \mathrm{~mL}$ was injected intracamerally and IOL was raised to inject approximately $1 \mathrm{~mL}$ into the capsule. Although a higher vitreous concentration was achieved than that with simple injection, there were 

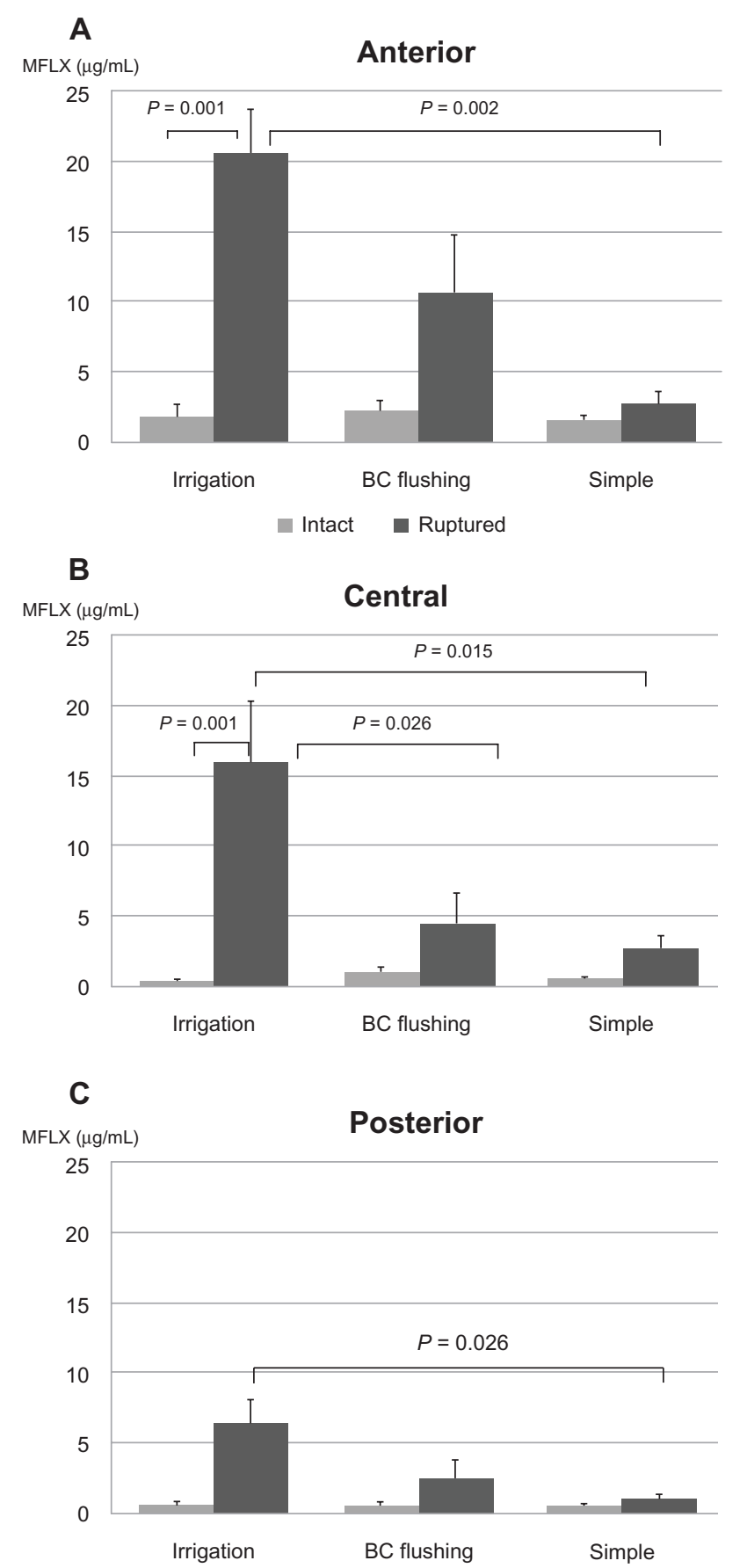

Figure 2 Average antibiotic concentration in anterior (A), central (B), and posterior (C) vitreous ( \pm standard error).

Notes: Irrigation solution administration, BC flushing and simple injection were compared in both intact and ruptured capsules.

Abbreviations: $\mathrm{BC}$, bag and chamber; MFLX, moxifloxacin.

cases of limited transfer to the vitreous. In order to reliably introduce a large amount of solution to the vitreous, IOL needs to be adequately elevated; however, it is difficult to conduct this procedure thoroughly in cases of ruptured capsule. Meanwhile, with irrigation solution administration, high vitreous concentrations were stably achieved with the lowest anterior vitreous concentration being $12.86 \mu \mathrm{g} / \mathrm{mL}$ (Table 1).

The fact that stable vitreous concentration can be achieved with only brief irrigation of the ruptured capsule means that vitreous contamination can readily occur when surgery is performed using contaminated irrigation solution containing no antibiotics. The status of the porcine eye is different from that of the human eye because intraocular pressure in the former is close to zero and the zonule is stronger. It was confirmed that the presence of a posterior capsule has a major influence on drug delivery and the risk of vitreous contamination.

We believe that in order to achieve effective vitreous drug concentration in cases with complications, simple injection and $\mathrm{BC}$ flushing are inadequate and the administration of irrigation solution containing antibiotics is required. Apparently, a vitreous contamination model was created with rabbit Staphylococcus sp. and intracameral administration of $1,000 \mu \mathrm{g}$ MFLX was found ineffective, but when $50 \mu \mathrm{g}$ of MFLX was injected into the vitreous (final estimated concentration, $17 \mu \mathrm{g} / \mathrm{mL}$ ), no bacteria were detected. In other words, even in an in vivo animal model, when vitreous contamination had occurred, intracameral administration could not prevent endophthalmitis, but intravitreal administration was found to be effective. ${ }^{17}$ These results are consistent with our findings that intracameral administration of antibiotics alone cannot achieve effective vitreous concentration when the posterior capsule is intact.

Even with vitreous MFLX administration exceeding the final estimated concentration of $300 \mu \mathrm{g} / \mathrm{mL}$ in the rabbit, it was reported as nontoxic on slit-lamp observation, indirect ophthalmoscopy, and corneal ultrasound and pachymetry. ${ }^{17}$ Kernt and colleagues ${ }^{18}$ reported that no irreversible changes occurred in cultured pigment epithelial cells with concentrations of up to $150 \mu \mathrm{g} / \mathrm{mL}$ of MFLX. The retinal safety of intravitreal MFLX in concentrations of $5-500 \mu \mathrm{g} / \mathrm{mL}$ was examined by electroretinography and histopathology in animal models. ${ }^{19} \mathrm{We}$ found that the maximum posterior vitreous concentration was 1.46 and $12.37 \mu \mathrm{g} / \mathrm{mL}$ in the intact and ruptured capsule, respectively (Table 1), and toxicity to the retina does not appear to be a problem at these levels. While cystoid macular edema has been reported with irrigation solution administration of vancomycin, ${ }^{20}$ there have been no such reports with MFLX, which is frequently used for intracameral administration. Although based on the results of an animal experiment, it has been reported that normal volumes of fluoroquinolones did not exhibit retinal toxicity. ${ }^{21}$ It cannot be denied that markedly high vitreous concentrations could 
have some type of effect, but even when considering reports of previous animal experiments, irrigation solution administration of approximately $150 \mu \mathrm{g} / \mathrm{mL}$ could at least be considered as not being of high risk. When a ruptured capsule is ascertained intraoperatively, 30-fold diluted (150 $\mu \mathrm{g} / \mathrm{mL})$ MFLX identical to that used in this experiment can be prepared by the addition of two new bottles $(10 \mathrm{~mL})$ of MFLX eye drop solution to a $300 \mathrm{~mL}$ bottle. If treatment after capsule rupture is carried out using this mixture, even if contamination occurs, the effective concentration of MFLX will reliably reach the contaminated vitreous simultaneously.

\section{Conclusions}

With an intact posterior capsule, intracameral MFLX exhibited limited effects on vitreous concentration. Despite the fact that the risk of infection clearly increases in cases of ruptured capsule, no special infection prevention protocol has been proposed. It was confirmed that irrigation solution can cause vitreous contamination in ruptured eyes within a short irrigation time. In this case, intracameral administration cannot necessarily achieve preventive concentrations for endophthalmitis, but it appears that an effective drug concentration will be achieved in the vitreous with irrigation solution administration.

\section{Disclosure}

The authors report no conflicts of interest in this work.

\section{References}

1. Hatano H. Experimental Pseudomonas endophthalmitis in rabbits. Intracameral inoculation of two pseudomonal strains. Nippon Ganka Gakkai Zasshi. 1982;86(8):839-845. Japanese.

2. Suzuki T, Wada T, Kozai S, Ike Y, Gilmore MS, Ohashi Y. Contribution of secreted proteases to the pathogenesis of postoperative Enterococcus faecalis endophthalmitis. J Cataract Refract Surg. 2008;34(10): 1776-1784.

3. Al-Mezaine HS, Al-Assiri A, Al-Rajhi AA. Incidence, clinical features, causative organisms, and visual outcomes of delayed-onset pseudophakic endophthalmitis. Eur J Ophthalmol. 2009;19(5):804-811.

4. Endophthalmitis Study Group, European Society of Cataract and Refractive Surgeons. Prophylaxis of postoperative endophthalmitis following cataract surgery: results of the ESCRS multicenter study and identification of risk factors. J Cataract Refract Surg. 2007;33(6):978-988.

5. O`Brien TP, Arshinoff SA, Mah FS. Perspectives on antibiotics for postoperative endopthalmitis prophylaxis: potential role of moxifloxacin. J Cataract Refract Surg. 2007;33(10):1790-1800.

Clinical Ophthalmology

\section{Publish your work in this journal}

Clinical Ophthalmology is an international, peer-reviewed journal covering all subspecialties within ophthalmology. Key topics include: Optometry; Visual science; Pharmacology and drug therapy in eye diseases; Basic Sciences; Primary and Secondary eye care; Patient Safety and Quality of Care Improvements. This journal is indexed on Submit your manuscript here: http://www.dovepress.com/clinical-ophthalmology-journal
6. Lane SS, Osher RH, Masket S, Belani S. Evaluation of the safety of prophylactic intracameral moxifloxacin in cataract surgery. $J$ Cataract Refract Surg. 2008;34(9):1451-1459.

7. Espiritu CR, Caparas VL, Bolinao JG. Safety of prophylactic intracameral moxifloxacin $0.5 \%$ ophthalmic solution in cataract surgery patients. $J$ Cataract Refract Surg. 2007;33(1):63-68.

8. Kawasaki S, Suzuki T, Yamaguchi M, et al. Disruption of the posterior chamber-anterior hyaloid membrane barrier during phacoemulsification and aspiration as revealed by contrast-enhanced magnetic resonance imaging. Arch Ophthalmol. 2009;127(4):465-470.

9. Fukuda M, Shibata N, Osada H, Yamashiro Y, Sasaki H. Vitreous and aqueous penetration of orally and topically administered moxifloxacin. Ophthalmic Res. 2011;46(3):113-117.

10. Lai WW, Chu KO, Chan KP, et al. Differential aqueous and vitreous concentrations of moxifloxacin and ofloxacin after topical administration one hour before vitrectomy. Am J Ophthalmol. 2007;144(2): 315-318.

11. Tzepi I, Vergados I, Kanellakopoulou K, et al. Pharmacokinetics of intravenously administered moxifloxacin in eye compartments: an experimental study. Int J Antimicrob Agents. 2009;33(2):160-162.

12. Matsuura K, Suto C, Akura J, Inoue Y. Bag and chamber flushing: a new method of using intracameral moxifloxacin to irrigate the anterior chamber and the area behind the intraocular lens. Graefes Arch Clin Exp Ophthalmol. 2013;251(1):81-87.

13. Kodjikian L, Renaud FN, Roques C, et al. In vitro influence of vancomycin on adhesion of a Staphylococcus epidermidis strain encoding intercellular adhesion locus ica to intraocular lenses. J Cataract Refract Surg. 2005;31(5):1050-1058

14. Chang DF, Braga-Mele R, Mamalis N, et al; ASCRS Cataract Clinical Committee. Prophylaxis of postoperative endophthalmitis after cataract surgery: results of the 2007 ASCRS member survey. $J$ Cataract Refract Surg. 2007;33(10):1801-1805.

15. Mendivil Soto A, Mendivil MP. The effect of topical povidone-iodine, intraocular vancomycin, or both on aqueous humor cultures at the time of cataract surgery. Am J Ophthalmol. 2001;131(3):293-300.

16. Matsuura K, Suto C, Akura J, Inoue Y. Comparison between intracameral moxifloxacin administration methods by assessing intraocular concentrations and drug kinetics. Graefes Arch Clin Exp Ophthalmol Epub April 2, 2013.

17. Kowalski RP, Romanowski EG, Mah FS, Yates KA, Gordon YJ. Intracameral Vigamox (moxifloxacin $0.5 \%$ ) is non-toxic and effective in preventing endophthalmitis in a rabbit model. Am J Ophthalmol. 2005;140(3):497-504.

18. Kernt M, Neubauer AS, Liegl RG, et al. Intracameral moxifloxacin: in vitro safety on human ocular cells. Cornea. 2009;28(5):553-561.

19. Gao H, Pennesi ME, Qiao X, et al. Intravitreal moxifloxacin: retinal safety study with electroretinography and histopathology in animal models. Invest Ophthalmol Vis Sci. 2006;47(4):1606-1611.

20. Axer-Siegel R, Stiebel-Kalish H, Rosenblatt I, Strassmann E, YassurY, Weinberger D. Cystoid macular edema after cataract surgery with intraocular vancomycin. Ophthalmology. 1999;106(9):1660-1664.

21. Penha FM, Rodrigues EB, Maia M, et al. Retinal and ocular toxicity in ocular application of drugs and chemicals - part II: retinal toxicity of current and new drugs. Ophthalmic Res. 2010;44(4):205-224.
PubMed Central and CAS, and is the official journal of The Society of Clinical Ophthalmology (SCO). The manuscript management system is completely online and includes a very quick and fair peer-review system, which is all easy to use. Visit http://www.dovepress.com/ testimonials.php to read real quotes from published authors. 